P1-31

\title{
DEVELOPING THE KNOWLEDGE MANAGEMENT SYSTEM BASED ON BUSINESS PROCESS
}

\author{
$\underline{\text { Sung Ho Jung }}{ }^{1}$, Ki Seok Lee ${ }^{1}$, Young Woong Song ${ }^{2}$, Hyoung Chul Lim ${ }^{3}$, and Yoon Ki Choi ${ }^{4 *}$ \\ ${ }^{1}$ Ph.D., Candidate, Department of Architectural Engineering, Soong sil University, Seoul, Korea \\ ${ }^{2}$ MEST-NRF Research Professor, Ph.D., Research Institute of Frontier Technology, Soong sil University, \\ Seoul, Korea \\ ${ }^{3}$ Assistance Professor, Ph.D., Department of Architectural Engineering, Changwon National University, \\ Changwon, Korea \\ ${ }^{4}$ Associate Professor, Ph.D., Department of Architectural Engineering, \\ Soong sil University, Seoul, Korea \\ * Corresponding author (ykchoi@,ssu.ac.kr)
}

\begin{abstract}
In the 21st century, knowledge has become one of the management paradigms which determines the organization competitiveness. Therefore, construction companies strive to strengthen the capacity of organization by introducing the knowledge management. However, the current knowledge management system applied in the construction industry is operated without a business process. Hence it could not provide the essential knowledge to each hands-on worker at a time when they are conducting work; it is simply used for organizing, accumulating, searching for knowledge. That being said, the utilization will show less than the amount of accumulation of knowledge. For these purposes, this study will build the knowledge-classification-system at the EPC(Engineering, Procurement, Construction) level based on business process and will develop the knowledge management system to increase the working-level utilization of building construction industry knowledge management system while improving usefulness of construction industry information management. This will profoundly improve the level of knowledge management of construction industry hereafter and be the basis of construction industry advancement, and contribute to expanding the base of knowledge management.
\end{abstract}

Keywords: KMS (Knowledge Management System), BP (Business Process), EPC (Engineering, Procurement, Construction)

\section{INTRODUCTION}

As the value of the intangible asset rises, creation and inflection of the knowledge provides the basis of the company`s competitiveness power, and the knowledge is positioned in the one of the management paradigms to control a competitive power of group. A dilemma serving the Knowledge of the company's core competency as recognition that the spread of knowledge management in academia and at the construction company has been a concern. In addition, the Republic of Korea introduced knowledge management in construction companies and building a knowledge management system used by the strengthening of the organization is concentrated. However, the current knowledge management system in the construction industry is operated without considering work process. Therefore, it is unable to provide the necessary knowledge to each hands-on worker at a time when they need. Moreover, it is simply used for organizing, accumulating and searching for knowledge, and the utilization is low compared with the amount of knowledge. For these reasons, this study will build the knowledgeclassification-system of the EPC level based on work process and develop the knowledge management system. This system would increase the working-level utilizing the building construction industry knowledge management 
system and improve usefulness of construction industry information management.

\section{DEFINITION OF KNOWLEDGE MANAGEMENT} BASED ON BUSINESS PROCESS

As shown in Figure 1, knowledge management based on business process analyzes the knowledge information of business process. When a unit business proceeds, the knowledge management provides predefined knowledge of business performance to practitioners of defined process steps. When re-created data is stored, it automatically sinks making feasible to accumulate data and to generate. To maximize the efficiency of work, decision support and knowledge management systems that accompany them derive knowledge stored in the DB input of another process will be used as knowledge base. Therefore, business and knowledge take place at the same time.

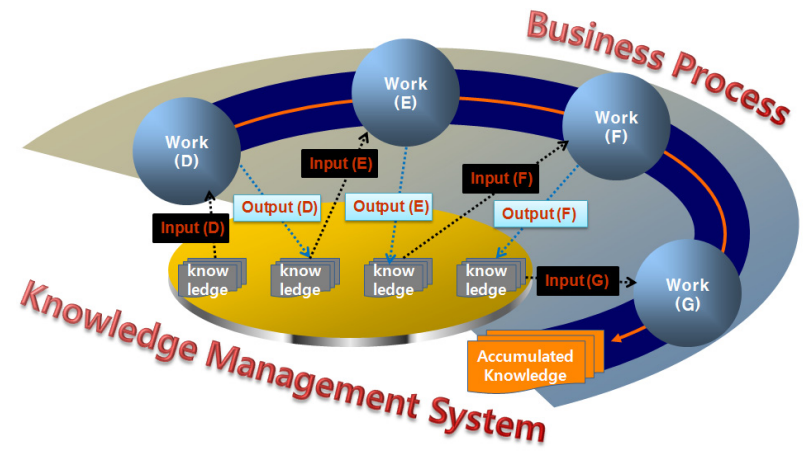

Fig. 1 Definition of knowledge management based on business process

\section{CONCEPT OF KNOWLEDGE MANAGEMENT SYSTEM MODEL BASED ON BUSINESS PROCESS}

Business process-based knowledge management system systematically presents time of required knowledge, knowledge of the subject and the target and the type of knowledge. Business process-based knowledge management system supports the EPC business and manages the knowledge effectively. Through business analysis, knowledge is provided to staff and also the knowledge of the time for each steps of the process is provided to staff in a timely manner. In addition, through ongoing process management, business process-based knowledge management system grasps the flow, storage and regeneration of knowledge. Thus, the business processbased knowledge management system utilizes them on subsequent process. Figure 2 shows the concept of knowledge management systems based on business process.

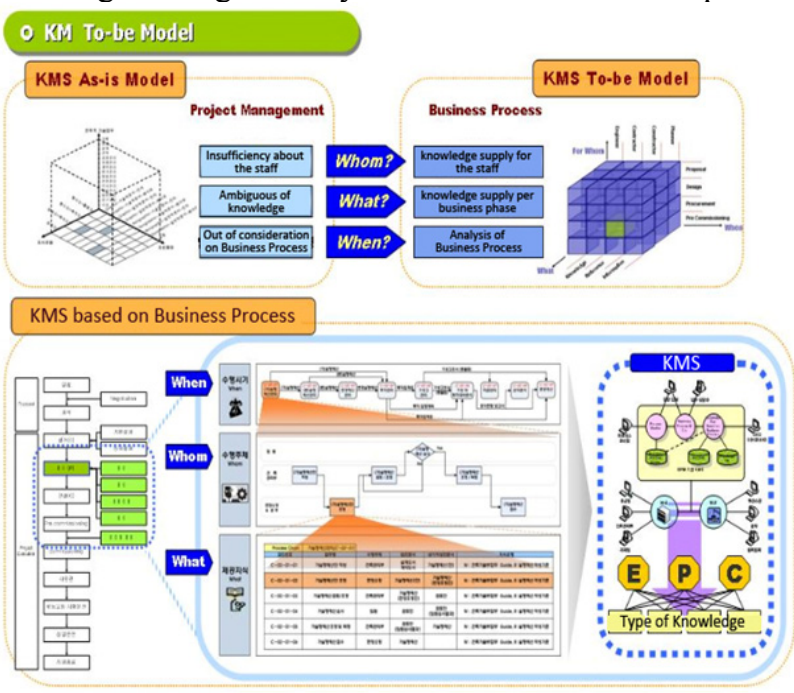

Fig. 2 The concept of knowledge management systems based on business process

\section{PRESENT OF KNOWLEDGE MANAGEMENT MODEL BASED ON BUSINESS PROCESS}

\subsection{Configuration of Knowledge management model based on business process}

When practitioners operates, the knowledge management system, based on its business process, offers information interconnecting modules; such as managers, business process engine, knowledge managers and monitoring system, to suggest necessary information. The process management team manages BPA (business process architecture), and the knowledge manager manages knowledge DB associated with the blogs. Knowledge map is created by BPA and knowledge DB, and practitioners will be provided knowledge timely. With attention to that, executives and business representatives will be able to monitor process and measure various performances. It supports the work by offering knowledge at the right time to subjects of headquarters, field and partners. The following picture shows an outline of the business processbased knowledge management system. 


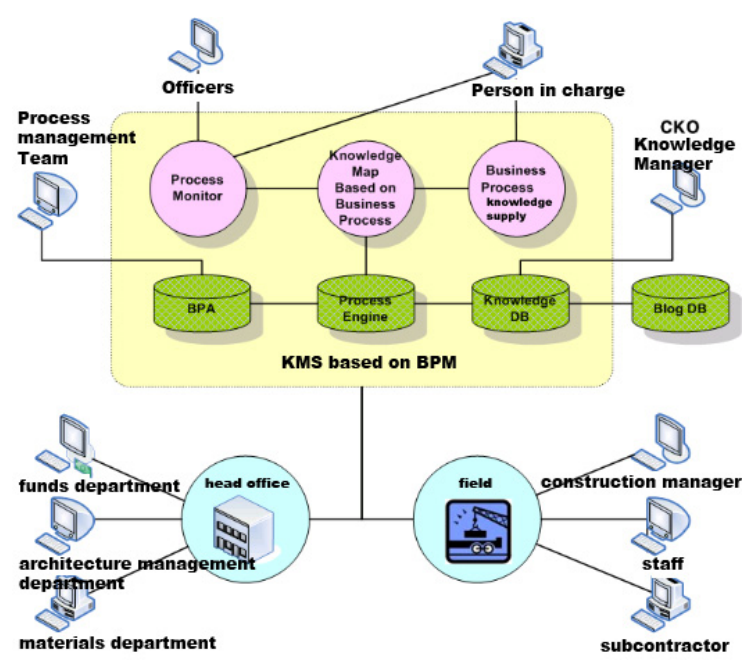

Fig.3 Business Process-based KMS outline

\subsection{Architecture of knowledge management model based on} business process

System module is composed as manager, business process engine module, knowledge manager, monitoring system. Manager module reflects improvement related to business, information support and work improvement. Business process engine is divided into business process $\mathrm{DB}$ and organization DB. It is a module that practitioners are provided to search, view, and detective work depending on code of business process architecture. Knowledge manager module includes knowledge to perform work and DB made four kinds of knowledge types. This knowledge DB is used to offer and register know-how linked with knowledge DB based on blog. Knowledge linked with business engine and knowledge manager is offered to users.

Monitoring system module provides work in progress along with the given subjects set period of work and work measurement. The following picture shows the business process-based knowledge management system architecture.

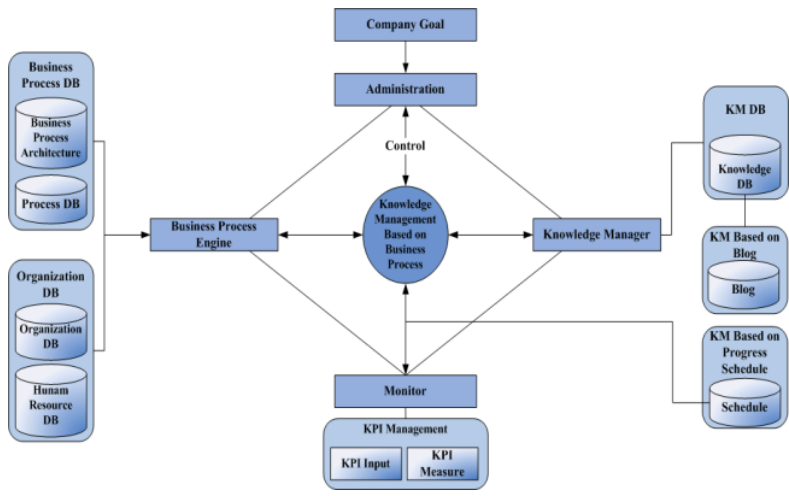

Fig. 4 Knowledge Management System Architecture

\subsection{Algorithm of knowledge management model based on business process}

By encoding the information in each module, modules are connected to implement and to operate knowledge management system based on business process. Subjects are constituted as organization DB of project engine by coding user information. This system is linked with a milestone-based system to obtain project information and further linked to a blog-based system to obtain blog list. With the given user ID, the user information will provide task title, start date, end date and working condition; such as FK(Foreign Key), by offering subjects to process work list made process code depending on process list. The following picture is ERD(Entity Relationship Diagram) of the knowledge management system based on business process.

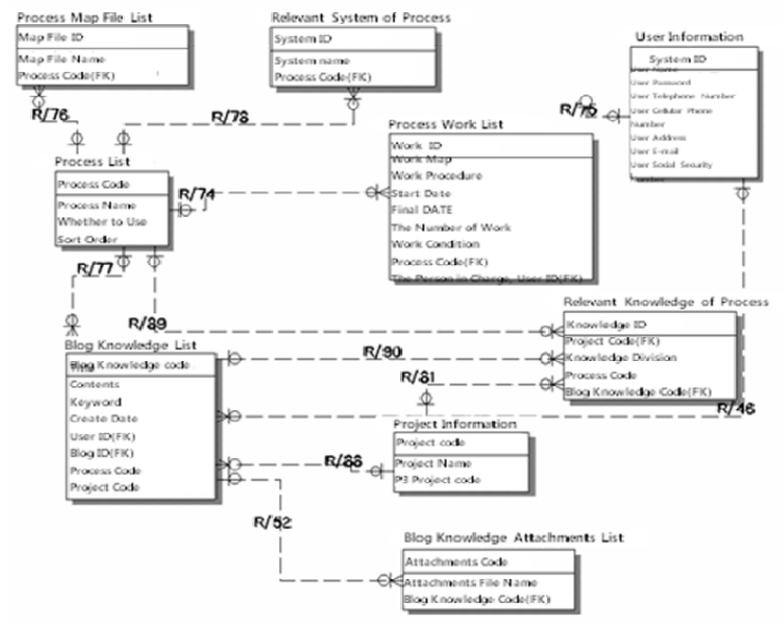

Fig.5. ERD of Knowledge Management system based on business process

\section{MODULE OF KNOWLEDGE MANAGEMENT SYSTEM BASED ON BUSINESS PROCESS}

Knowledge of business process management system based on the EPC phase is performed based on the specific business processes, which are configured by the user in the system visible to the qualified business process execution ;and thus, it should take more lines of business, trailing identify business relationships, knowledge Perform such tasks as viewing and registration is available.

The main user interface of business process-based knowledge management system is followed by the Figure 6 . 


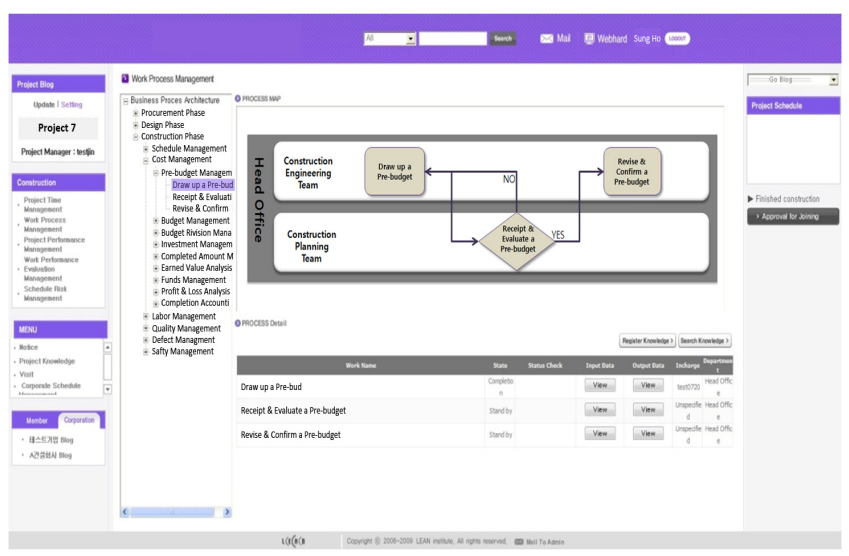

Fig.6. Business Process-based Knowledge Management

System Main User Interface

\subsection{Business Process hierarchy}

When looking at the main User Interface system to the left on the screen, the EPC phase of the business process level will be shown. It is completed so that the user can go find via menu structure in the form of a tree. When users click on the want to work, the business process map and detailed information is displayed on the screen and they can use functions of visualization and monitoring of business processes. The construction consists atypical processes per project. To compensate, knowledge management system can add, edit and delete to process. User interface of process edit is followed by the Figure 7 .

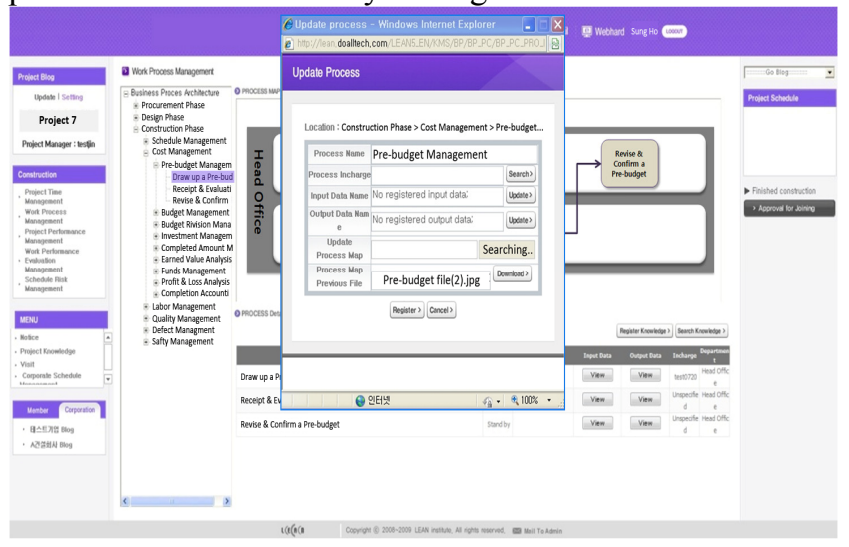

Fig.7. User interface of process edit

\subsection{Business Process Visualization}

When users click on the want to work button, it is shown in the form of the Process Map in the center of the screen, and it can easily be found to spot where their work and what the following task is. It is considered process related subjects, order relationship, decision details for effective management and shown process which will be used to work and monitor process.

\subsection{Business Process Monitoring}

For managing knowledge within the business process, work in progress should be monitored. When users click on the want to work button, the screen is shown the current work progress and could check the status, Input / Output Data, subject performed, department, knowledge register and knowledge search.

The process of the work can be monitored via process detailed information; further, if previous person's work is completed, related knowledge for the work could be provided next person by identifying the delivery status following the work on time.

\subsection{Knowledge Search}

If KMS is not either well-organized or difficult to use, it will be effortless to consider searching knowledge as another task. To facilitate the search of knowledge, function of Knowledge Search is performed. When Knowledge Search tab is clicked, Knowledge search box will open, and users can easily search for information from Keyword, and the information is provided by the type of knowledge as shown following picture.

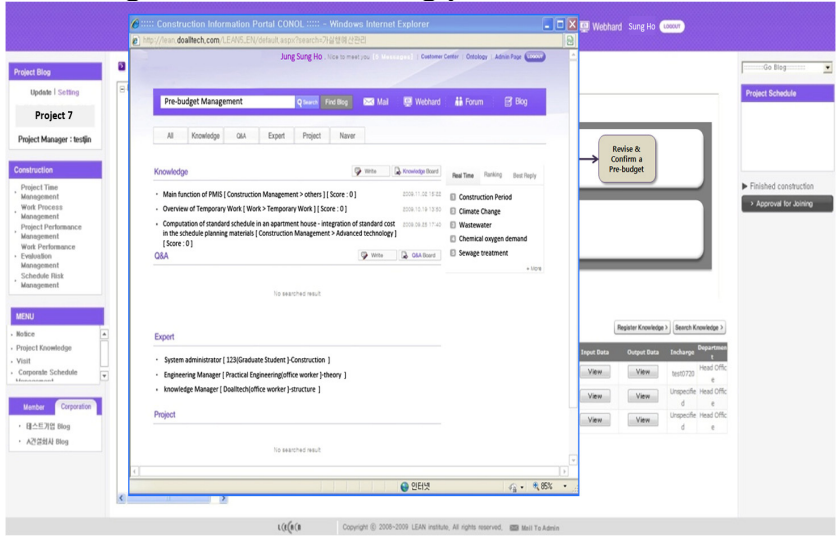

Fig.8. Knowledge Search User Interface

\subsection{Knowledge Register}

Knowledge Register provides not only function of reading knowledge but also function of registering the knowledge that occurs along business process by users. When users register their knowledge, a level is divided into three levels that are big scope (value chain), middle scope (mega process), and small scope (process chain). Registration 
procedures simplify, and the creation of knowledge facilitates by writing the title and contents by users.

The following picture shows knowledge register user interface.

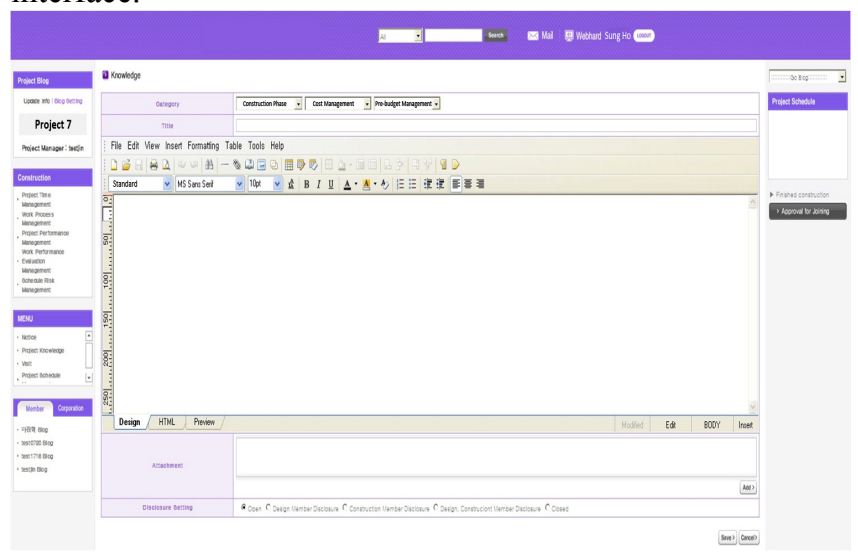

Fig.9. Knowledge Register User Interface

\section{BUSINESS PROCESS-BASED KNOWLEDGE MANAGEMENT SYSTEM BENEFITS}

To demonstrate the expected effects of knowledge management system based on business process, the practitioners were interviewed. Three domestic construction companies and two engineering companies were recruited to interview. The respondents have worked an average of five to ten years for the companies. The interview was conducted by answering on a scale from one to five points about the rationality of knowledge classification configuration, evaluation of user for change management of business process, evaluation of knowledge utilization and benefits of knowledge management system. Table 1 outlines the survey to analyze the expected outcomes of the knowledge management system based on business process.

Table 1. Survey outlines

\begin{tabular}{|c|c|}
\hline Category & Survey outline \\
\hline $\begin{array}{l}\text { Subject of } \\
\text { survey }\end{array}$ & $\begin{array}{l}\text { Improvements and efficiency of knowledge } \\
\text { management system based on business process } \\
\text { compared with existing system. }\end{array}$ \\
\hline period & May $1 \sim 24,2010$ \\
\hline $\begin{array}{l}\text { The target o } \\
\text { survey }\end{array}$ & $\begin{array}{l}\text { The staffs worked for } 5 \sim 10 \text { years on construction } \\
\text { and engineering companies }\end{array}$ \\
\hline $\begin{array}{l}\text { Survey } \\
\text { method }\end{array}$ & $\begin{array}{l}\text { 1st: Introduction and interview possibility by } \\
\text { telephone interview Check } \\
\text { 2nd: interview method explain / Questionnaire } \\
\text { distribute by e-mail }\end{array}$ \\
\hline
\end{tabular}

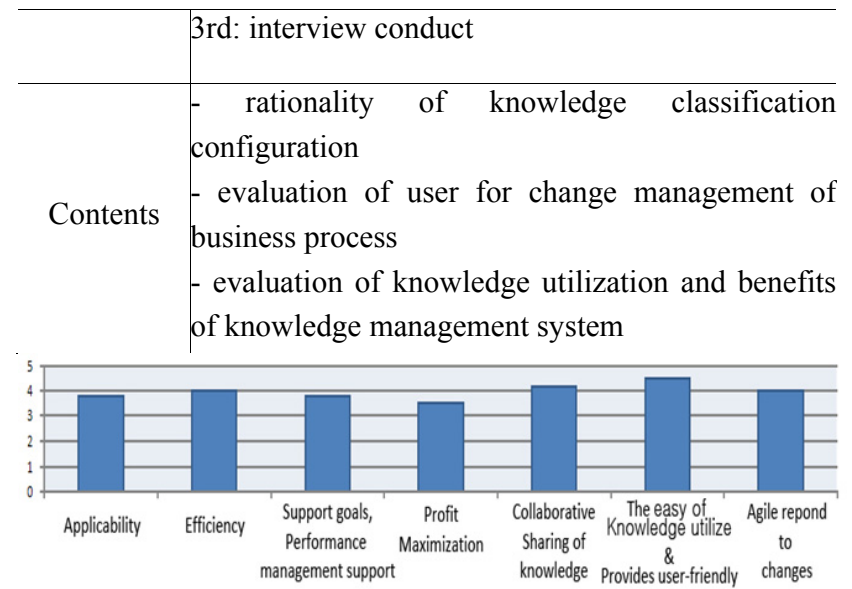

Fig.10. Business process-based knowledge management system benefits

The figure 10 appeared to have a high expectation about the knowledge management system based on business process. These results explain that this system would increase the working-level utilization of building construction industry knowledge management system while improving usefulness of construction industry information management. Business process visualization and monitoring System support to identify work progress and manage business process. Since each practitioner is provided the knowledge required at the time of need, they can improve work efficiency minimizing inadequate activities. In addition, the knowledge generated in the work can immediately take advantage of registers, and the accumulation of knowledge can increase the utilization thereafter. Business process-based and responsive is subject to change; consequently, flexibility in the foundation will be able to support business operations.

Furthermore, strategic connection can be promoted by supporting goals and performance management. This is to maximize profit and help companies to achieve their goals. That being mentioned, the flow of the business processbased knowledge, the formation of the organizational culture of collaboration, knowledge sharing and continuous utilization culture will be formed.

Table 2 shows the benefits of the knowledge management system based on business process in regards to technical aspects, social and economic aspects, aspects of influence into other industries. 
Table 2. Business Process-based Knowledge Management System Benefits

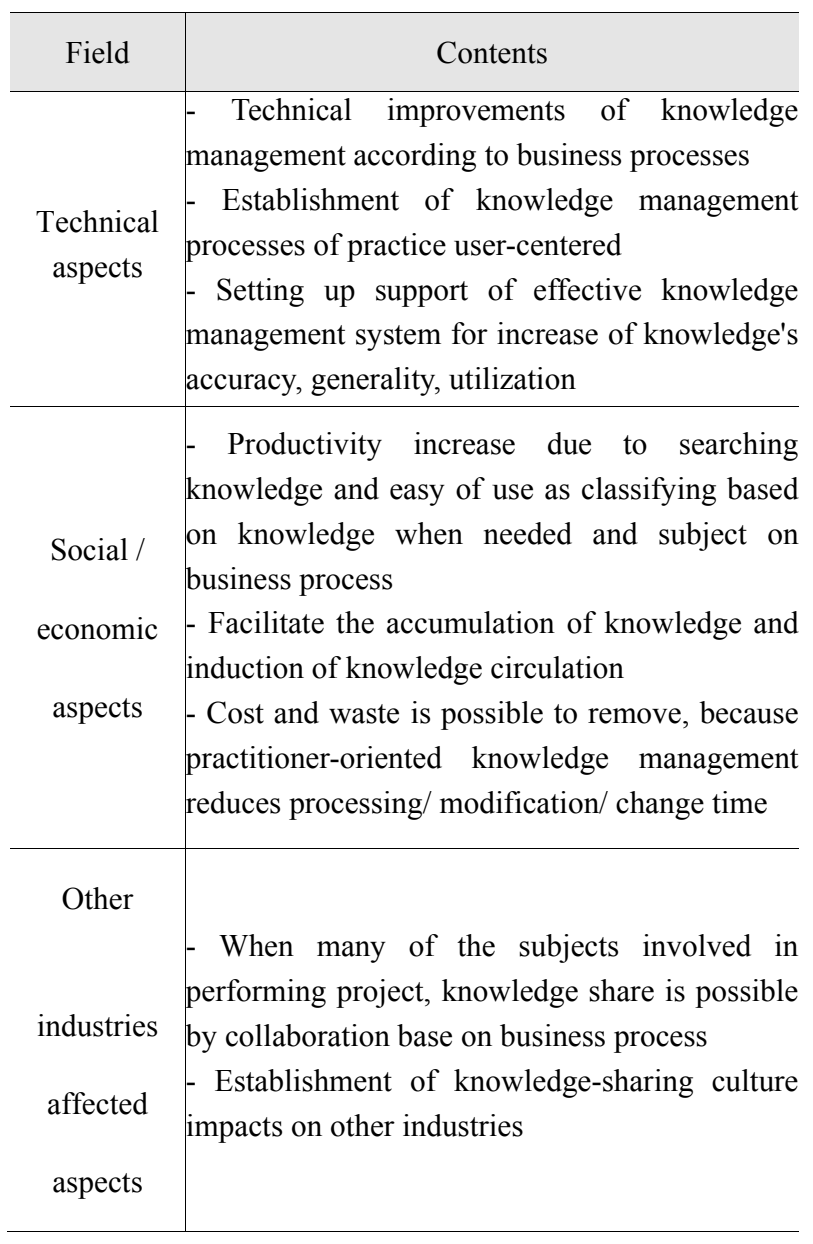

\section{CONCLUSION}

Many construction companies currently use knowledge management systems, yet they do not provide the necessary knowledge. It is because already applied knowledge management system do not consider the practical user and do not reflect the business processes. When users need to find the knowledge necessary, knowledge necessary for the required time is not provided to subjects. Therefore, knowledge management system utilization is low compared to the accumulation of knowledge.

In this study, knowledge management system was developed for the vital growth of practical utilization of knowledge management systems for construction industry to improve the effectiveness of information management in business processes based on Knowledge classification system of the EPC phase.
This is the future of the construction industry to improve the level of knowledge management. More importantly, the knowledge management will achieve construction advancement and will be a foundation to contribute expanding base of knowledge management

\section{Acknowledgement}

This work was supported by the National Research Foundation of Korea Grant funded by the Korean Government(Ministry of Education, Science and Technology). [NRF-2010-359-D00027]

\section{REFERENCES}

[1] Sang-Soo, Kim, Young-Woo, Kim , “An Empirical Study on the Key success Factors of Knowledge Management" , Korean Academic Society of Business Administration, Vol.29(4), pp.585 616, 2000

[2] Tae-Chul, Kim "A study on the Business Process-based Knowledge Management System Model” , Graduate School of Information \& Communication Technology University of Ulsan, 2005.6.

[3] Hye-Kyung, Kim "A case study on the Success Factors of public firm`s Knowledge Management System", Graduate School of Business Administration Sogang University, 2002.2.

[4] Jong-Keon, Baik, Jea-Jun, Kim , “ Implementing Knowledge Management(KM) for a competitive enhancement in Construction Company", Journal of the Architecture Institute of Korea, Vol. 19(3), pp.131-138, 2003.

[5] Young-Woong, Song, "A study of a Sustainable Business Process Management Model for a Construction Company", Department of Architecture Graduate School Soongsil University, 2007.6.

[6] John Heston \& Hohan Nelis, "Business Process Management : Practical Guidelines to Successful Implementations" , Butterworth-Heinemann, 2006

[7] Smith. H. \& P. Finger, "The Business Process Management Scenario", 2003. 